University of Nebraska - Lincoln

DigitalCommons@University of Nebraska - Lincoln

Educational Psychology Papers and

Publications

Educational Psychology, Department of

May 2005

\title{
A Contextual Approach to the Assessment of Social Skills: Identifying Meaningful Behaviors for Social Competence
}

\author{
Emily D. Warnes \\ University of Nebraska-Lincoln, emwarnes@yahoo.com \\ Susan M. Sheridan \\ University of Nebraska-Lincoln, ssheridan2@unl.edu \\ Jenenne Geske \\ University of Nebraska Medical Center-Omaha \\ William A. Warnes \\ University of Nebraska Medical Center
}

Follow this and additional works at: https://digitalcommons.unl.edu/edpsychpapers

Part of the Educational Psychology Commons

Warnes, Emily D.; Sheridan, Susan M.; Geske, Jenenne; and Warnes, William A., "A Contextual Approach to the Assessment of Social Skills: Identifying Meaningful Behaviors for Social Competence" (2005).

Educational Psychology Papers and Publications. 3.

https://digitalcommons.unl.edu/edpsychpapers/3

This Article is brought to you for free and open access by the Educational Psychology, Department of at DigitalCommons@University of Nebraska - Lincoln. It has been accepted for inclusion in Educational Psychology Papers and Publications by an authorized administrator of DigitalCommons@University of Nebraska - Lincoln. 


\title{
A Contextual Approach to the Assessment of Social Skills: Identifying Meaningful Behaviors for Social Competence
}

\author{
Emily D. Warnes and Susan M. Sheridan \\ University of Nebraska-Lincoln \\ Jenenne Geske and William A. Warnes \\ University of Nebraska Medical Center
}

\begin{abstract}
An exploratory study was conducted which assessed behaviors that characterize social competence in the second and fifth grades. A contextual approach was used to gather information from second- and fifth-grade children and their parents and teachers regarding the behaviors they perceived to be important for getting along well with peers. Data were gathered from children through structured interviews with the researcher. Parents and teachers provided information through open-ended paper-pencil surveys. Qualitative methodology was used to analyze the data in this study. Specifically, a threestage coding process derived from grounded theory was utilized (A. Strauss \& J. Corbin, 1998). Triangulation, a technique common to qualitative research whereby multiple sources are used to verify themes identified from data, also was used throughout the coding process to enhance standards of rigor (J.W. Creswell, 1998). Results indicated substantial overlap among the types of behaviors reported by children, parents, and teachers in both grades. Likewise, a number of noteworthy similarities and differences were found among second- and fifth-grade sources. Findings are discussed in terms of their implications for social skills assessment and intervention. Limitations and directions for future research also are discussed.
\end{abstract}

Effective social functioning is a critical factor in child development. Children who lack important social skills often are rejected by their peers, have trouble interacting with their teachers and families, and have emotional difficulties (Coie \& Dodge, 1988; Dodge, 1983; Parker \& Asher, 1987; Vosk, Forehand, Parker, \& Rickard, 1982). Furthermore, social skills deficits are frequently associated with children exhibiting externalizing disorders such as delinquency and conduct disorder, as well as those with internalizing disorders like depression and anxiety (Mash \& Barkley, 1996). Because social competence has a significant impact on development, identifying behaviors that are meaningful in children's social networks is of critical importance. The purpose of the current study was to identify meaningful social behaviors within two different developmental levels (second and fifth grades) using a contextualized assessment approach whereby relevant sources in children's lives (i.e., parents, teachers, and peers) were asked to report the behaviors they deemed important for social competence.

\section{What Are Social Skills?}

Researchers have defined social skills in a number of ways. Often a distinction is made between social skills and social competence. Social skills typically refer to discrete, goal-directed behaviors that allow an individual to interact effectively with others in his or her environment (Sheridan \& Walker, 1999), whereas social competence generally refers to the quality of an individual's social interactions as perceived by those around him or her (Gresham, 1986; McFall, 1982). Taken together, it emerges that for children to attain social skillfulness, they must not only acquire important social behaviors for interacting with others, but must be able to use these skills in ways that are acceptable to others in their environment (Sheridan \& Walker, 1999).

The authors would like to acknowledge the following individuals for their important contribution to this study through coding of research data: Melissa Brown, Brandy Clarke, Shannon Dowd, Diane Marti, and Ariadne Schemm.

Corresponding author: Emily D. Warnes, Munroe-Meyer Institute, 985450 Nebraska Medical Center, Omaha, NE 68198. E-mail: emwarnes@yahoo.com 
Social behaviors do not occur in isolation; thus, the various factors that influence children's social functioning should be considered. A contextual approach to understanding social competence requires that we not only consider the goals and motivations of social behavior from the child's perspective, but that we consider the responses of others in the environment which reinforce or discourage the social behavior of the child (Haring, 1992; Sheridan \& Walker, 1999). Socially skilled individuals are able to understand the perspectives of others and react appropriately. This principle can be understood by considering the various settings in which children frequently interact such as at school and home. Each of these settings clearly requires different behaviors for appropriate social functioning, as the expectations and normative behavior vary across home and school contexts. Children must be able to negotiate the differences in expectations and demands across settings and behave in a way that adapts to the parameters of the context.

\section{Traditional Assessment of Social Skills}

Social skills assessments have traditionally focused on identifying individual social deficiencies within a child and evaluating treatment outcomes (Sheridan \& Walker, 1999). Researchers and practitioners have used a variety of methods by which to assess children's social skills. One of the most common assessment techniques includes using the evaluations of others (e.g., ratings and reports of peers, teachers, and parents). Rating scales are one way that information can be gathered from others in a child's environment (Elliott \& Bussee, 1991; Merrell \& Gimpel, 1998; Sheridan \& Walker, 1999). These scales require teachers and/or parents to rate children on a number of specified criteria. In addition to providing information about a child's individual social behaviors, many of these scales are standardized and allow for a comparison of the child's behavior to that of a same-aged norm group.

Teacher nominations and rankings comprise an additional evaluative assessment of a child's social skills (Elliott \& Busse, 1991; Foster, Inderbitzen, \& Nangle, 1993; Sheridan \& Walker, 1999). Using this technique, teachers are asked to provide a list of students who demonstrate a specific behavioral characteristic to the greatest or least extent in comparison to classmates (e.g., "is the most cooperative" or "is the most disruptive"). This allows for a relative comparison of a child's social skills to that of other children in the classroom. Peer ratings and/or nominations (i.e., sociometrics) are conducted in much the same way with peers rating or nominating other children according to specific behavioral characteristics.

Self-report provides information about a child's subjective perceptions of his or her own social competence (Elliott \& Busse, 1991; Foster et al., 1993; Merrell \& Gimpel, 1998; Sheridan \& Walker, 1999). This technique requires that a child report thoughts and opinions about his or her social behaviors and relationships. Children also can be asked to report how they would handle various social situations or interactions. Although self-reports can provide unique information regarding a child's perceptions of his or her social behavior, the subjective nature of this technique precludes criterion-related validity and as such, is not often used as a stand-alone procedure for assessing social competence.

Direct behavioral observation is another method of assessing a child's social skills (Elliott \& Busse, 1991; Foster et al., 1993; Merrell \& Gimpel, 1998; Sheridan \& Walker, 1999). Using an observational coding system that defines specific categories of behavior, observers can record the behavior of a child over a period of time. When conducted in a naturalistic setting, behavioral observation allows for an understanding of the frequency and range of social behaviors in the child's repertoire, as well as a look at the function of the child's behavior in the environment (e.g., any influential antecedent, sequential, or consequential conditions that may maintain or discourage social behavior). 


\section{Limitations of Traditional Assessment Procedures}

Each of the aforementioned assessment techniques provides unique information regarding a child's social skills; however, these methods tend to emphasize intra-individual variables (e.g., the child's knowledge and performance of various social behaviors), giving little attention to the contextual factors that impact social functioning (Haring, 1992; Sheridan, Hungelmann, \& Maughan, 1999; Sheridan \& Walker, 1999). As a result, these assessments provide information regarding the various behaviors that a child does and does not exhibit. It is often assumed that based on this information, interventions can be developed by looking at excesses and deficits in the child's behavioral repertoire and teaching appropriate behavioral adjustments. Unfortunately, the use of behavioral excesses and deficiencies to determine targets for intervention fails to account for the meaningfulness of various social behaviors within a given context. Even though new behaviors may be taught to the child, these behaviors may not be functional within that child's social network (Haring, 1992). Despite the fact that parents, teachers, and peers can provide helpful information regarding a child's specific behaviors, these sources are not generally questioned about the types of behaviors that are relevant and meaningful within the child's social environment. Little information is provided regarding the specific skills that are important for the child to learn to get along with others and increase his or her status within the social network. Although a few assessment procedures such as the Social Skills Rating System (SSRS; Gresham \& Elliott, 1990) account for both parents' and teachers' perspectives regarding the importance of social behaviors (i.e., the SSRS asks raters to rate the importance of each social skill on a 3-point scale), these are few and far between. Furthermore, the scores derived from the SSRS are based solely on reported frequency levels of prespecified behaviors for targeted children at home and school. Children's scores do not reflect the importance ratings or those behaviors necessary for appropriate interaction in the environment.

\section{Contextual Approach to Social Skills Assessment}

A contextualized approach is essential for determining the types of social skills that are meaningful in a child's social network. Although many practitioners and researchers advocate for a multimodal approach to social skills assessment (i.e., the incorporation of various methods, sources, and settings into the assessment process; Carey \& Stoner, 1994; Elliott \& Busse, 1991; Gresham, 1995; Maag, 1989; Sheridan et al., 1999; Sheridan \& Walker, 1999; Walker, Irvin, Noell, \& Singer, 1992), this assessment approach is rarely used (Maag, 1989; Sheridan et al., 1999). In keeping with a contextual framework for understanding social skills, not only must the behaviors and perspectives of an individual child be examined, but the social responses and expectations of the environments in which that child interacts also must be accounted for (Haring, 1992; Sheridan et al., 1999; Sheridan \& Walker, 1999).

Researchers have emphasized the importance of incorporating contextually meaningful information into intervention programming and evaluation. Kazdin (1977) highlights the importance of the evaluation of others in determining the meaningfulness of treatment outcomes. A critical component in determining the significance of a behavior change for a particular client involves assessing the functioning of the client within a given social context after the behavior change has occurred (Kazdin, 1977). Thus, the validity of behavioral interventions rests on the reactions and perceptions of others in the client's social context to the new behaviors exhibited by the client.

The importance of socially valid treatment outcomes has implications for social skills assessment and intervention programming. Not only must children learn various prosocial behaviors, but these behaviors must be meaningful within their social networks. It is only when social behaviors are meaningful that they are reinforced in the child's social context and the process of "behavioral 
entrapment" may occur whereby newly learned social responses come under the control of naturally occurring reinforcers (McConnell, 1987). Within this framework, newly learned social behaviors must be naturally reinforced to generalize to a child's natural environment (Fox \& McEvoy, 1993; McConnell, 1987). When others in the environment reinforce the social skills being used, children are more likely to continue to use the skills on a regular basis. Because parents, teachers, and peers are relevant information sources, it can be assumed that the social behaviors rated highly by these sources may be those that will be naturally reinforced in the environment.

The necessity of considering contextual information such as that provided by teachers, peers, and independent observers in social skills assessment and programming has been discussed in the social skills literature. Sheridan and colleagues (1999) describe a procedure designed to gather contextually relevant information regarding the behavior of socially competent children. Specifically, with this procedure, teachers, peers, and independent observers each could provide a written list of behaviors that are deemed important for children's social competence. In gathering information from these various sources, specific behaviors could be identified that correspond to social competence for a particular group of children within a given context. The identified behaviors would, in essence, comprise a "template" for social competence. Similarly, "template matching" has been suggested as a technique to identify important social behaviors of children (Hoier \& Cone, 1987). In one study, 8- and 9-year-old children participated in a 50-item Qsort procedure to identify specific behaviors that were critical for being a good friend (Hoier \& Cone, 1987). The identified behaviors were described as comprising a "template" of a socially competent child. These "template" behaviors were validated by manipulating the behaviors in nonscripted confederates and assessing the impact of the manipulations on behavioral and sociometric measures from the original subjects involved in the Q-Sort procedure. Results indicated that the template behaviors were preferred and led to increased sociometric ratings of confederate children.

The template created through the assessment procedure described by Sheridan et al. (1999) eventually could be used to help identify target behaviors for social skills interventions by comparing the behaviors of children with social difficulties to those behaviors on the template. Any behaviors on the template for social competence, but not exhibited by the child with social difficulties, could be targets for intervention. Although this assessment procedure has undergone some pilot experimentation, very little research has been conducted in this area.

The current study expands the research on contextualized approaches to the assessment of social skills. A procedure similar to that outlined by Sheridan et al. (1999) was used to gather information from parents, teachers, and peers regarding the specific behaviors that are important for social competence in second- and fifth-grade children. The purpose of this exploratory study was to identify the types of behaviors that relevant sources (i.e., parents, teachers, and peers) reported as meaningful for social competence at two different developmental levels (second and fifth grades). Specific research questions included: (a) What behaviors do parents, teachers, and children report as important for being a good friend in the second and fifth grades?, and (b) What similarities and differences are there among the types of behaviors reported by relevant sources within each developmental level?

\section{Methods}

\section{Participants and Setting}

The participants for this study included second- and fifth-grade children and their respective teachers and parents. Participants were recruited from two public elementary schools located in Lin- 
coln, Nebraska. Both schools were large in size, serving approximately 600 children. The average class size for each of the schools was approximately 20-25 students. The schools served students who generally came from middle to lower-middle socioeconomic households. For second grade, a total of 45 children, 37 parents, and 8 teachers participated in the study. Of these, $47 \%$ of children and $13 \%$ of teachers were male. For fifth grade, a total of 36 children, 38 parents, and 10 teachers participated. Of these, $44 \%$ of children and $50 \%$ of teachers were male. Gender of second- and fifthgrade parent participants is unknown.

A letter describing the research study and corresponding consent form was sent to the parents and legal guardians of the recruited children. Parents were provided four options for consent: (a) their child's participation only, (b) their own participation only, (c) both their child's and their own participation, or (d) neither their child's nor their own participation. Only those children whose parents or legal guardians consented for their participation were allowed to participate in the study. Second- and fifth-grade teachers from the two schools were recruited. Teachers received a letter describing the research study and were required to sign a consent form before participating.

\section{Data Collection}

Parent and teacher surveys. Data were gathered from children, parents, and teachers regarding their perceptions of the behaviors that are important for social competence. Parents and teachers were provided an open-ended survey requesting them to list specific behaviors that are important for children of their respective child's age to get along well with peers. There was no limit to the number of responses that parents and teachers could report. Parents and teachers were encouraged to list as many behaviors as possible.

The survey for parents read:

Think about your child and his or her peers. What are the kinds of things that children this age need to do to get along well with their peers? List the specific behaviors that you think are important for children to show they are good friends to others. Please be specific in your responses by describing actual observable behaviors. Identify as many behaviors as you can think of.

The teachers' survey read:

Think about your students and the behaviors they must perform to get along with their peers. Consider specific students who appear to be socially competent and have a lot of friends. What are the kinds of things that these children do to show they are good friends to others? List the specific behaviors that you think are important for your students to be good friends. Please be specific in your responses by describing actual observable behaviors. Identify as many behaviors as you can think of.

Child interviews. Data from children were collected through individual structured interviews with a researcher. A total of 45 interviews were conducted with second-grade children and 36 interviews were conducted with fifth-grade children (i.e., one per participant). All interviews were conducted during the school day and in a private room, free from distractions, with the researcher. From observation and teacher report, children generally enjoyed participating in the interviews and having individual time with the researcher. Interviews lasted approximately 10 minutes per child. The researcher began the interview by using an open-ended statement to elicit responses from children: "Think about some people who you consider good friends. There are probably things they do to let you know they are good friends. What kinds of things do you see them do that let you know they are good friends?" The researcher implemented structured follow-up questioning in cases where vague or nonbehavioral responses were provided by children. For example, if the child reported that good friends "are nice," the researcher asked him/her to be specific in the response through questions such 
as, "What kinds of things do good friends do to show you they are nice?" During the interview, the researcher encouraged child participants to think of as many responses as they could, using questions such as "Anything else?" and "Can you think of anymore?" All interviews were audiotaped to allow for the analysis of interview integrity.

\section{Data Analysis}

Qualitative methodology was used to analyze the data in this study. Specifically, a three-stage coding process derived from grounded theory was utilized (Strauss \& Corbin, 1998). Triangulation, a technique common to qualitative research whereby multiple sources are used to verify themes identified from data, also was used throughout the coding process to ensure that standards of rigor were met (Creswell, 1998).

Open coding. The first stage in grounded theory methodology is open coding (Strauss \& Corbin, 1998). Open coding involves the examination, comparison, conceptualization, and categorization of data. Raw data are examined for similarities and differences, and initial conceptual categories or phenomena are identified (Strauss \& Corbin, 1988).

In the open coding stage of data analysis for the current study, preliminary response categories were identified by examining similarities in responses (Strauss \& Corbin, 1998). Initial examination of the data revealed a considerable number of responses by child, parent, and teacher participants. The mean number of responses for individual child participants were $5(R=2-14)$ and 6 $(R=3-20)$ for second and fifth graders, respectively. The mean number of parent responses was 9 $(R=3-18)$ and $8(R=3-18)$ for second- and fifth-grade parents, respectively. For teacher respondents, the mean number of responses was $12(R=5-18)$ and $8(R=4-17)$ for second- and fifthgrade teachers, respectively.

Within respondent groups (i.e., children, parents, teachers), participants often provided very similar responses (e.g., "they don't take things from you," "they don't steal," "they don't steal your things"). To eliminate redundancy and create a manageable working data set for the next stage of data analysis (see axial coding below), comparable responses were collapsed into a single category for each data set (second- and fifth-grade children, parents, and teachers). The principal researcher identified some initial response categories for each data set (second- and fifthgrade children, parents, and teachers) and coded the data to reflect these categories. Categories were derived for only those responses where there was an obvious similarity in theme (e.g., "helps with math" and "helps with English" were coded as "helps with academics"); thus, not all responses were captured by these categories. Two research assistants coded the same data for verification purposes. Research assistants were provided the categories identified by the principal researcher and told to code the data set by identifying any responses that fit within the provided categories. The number of agreements over disagreements was calculated against the primary researcher's response codes, yielding $93 \%$ and $95 \%$ reliability scores, respectively, for the two raters. Through open coding, each of the six data sets (second-grade children, parents, and teachers, and fifth-grade children, parents, and teachers) comprising total responses from participants were reduced in size from 241 to 101 unique responses (second-grade children), 339 to 207 responses (second-grade parents), 89 to 68 responses (second-grade teachers), 215 to 125 responses (fifth-grade children), 317 to 226 responses (fifth-grade parents), and 79 to 68 responses (fifthgrade teachers).

Axial coding. The second stage of data analysis in grounded theory methodology is axial coding, a process whereby data are put together in new ways by making connections between responses or 
categories (Strauss \& Corbin, 1998). Emphasis is on specifying categories or phenomena based on the context or conditions that influence various responses (Strauss \& Corbin, 1998).

In the current study, axial coding allowed the researcher to assemble the data in new ways and form additional response categories. During axial coding, all response categories identified in the open coding stage and those responses not coded into categories were used in a card sort procedure. All responses were placed on index cards and sorted into piles based on similarities in theme. Two research assistants sorted each of the six data sets (second-grade children, parents, and teachers, and fifth-grade children, parents, and teachers). The research assistants were instructed to sort the cards into as many piles as they saw fit based on similarities and theme. There were no limits to the number of cards in each pile or the number of piles that could be created for each data set. Additionally, research assistants were instructed not to label their sorted piles, as these piles would be analyzed through other means by the primary researcher (see selective coding below).

Selective coding. The last stage of the coding process is selective coding (Strauss \& Corbin, 1998). This stage involves selecting the core categories and relating them to one another. Categories are further refined and integrated, and a grounded theory or phenomenon is developed (Strauss \& Corbin, 1998).

In selective coding, the researcher identified general response themes that emerged from each of the data sets. Data from the card sorts were utilized in this stage by assessing the specific responses that were placed in the same pile by both sorters. The researcher reviewed all sorted piles and identified specific responses that clustered together in the piles sorted by both of the research assistants. When responses were sorted in the same pile by both sorters, the primary researcher generated a label for these themed responses. Using this process, general themes for each of the six data sets were identified. Responses that comprised their own pile by either of the sorters were not considered for inclusion in the final labeling of themes. In this way, the final labels for social behaviors for each category were created from clusters rather than individual responses.

\section{Integrity of Child Interviews}

Integrity of the child interviews was assessed to ensure that the researcher used the same interview procedures for each child. All interviews were audiotaped and a checklist was created that detailed four specific interview objectives (i.e., interviewer's use of an open-ended statement to begin the interview, follow-up questioning for vague responses, questioning to elicit additional responses and determine if the child was finished responding, and effectively terminating the interview when the child was finished responding). Thirty-three percent of the second- and fifth-grade interviews (i.e., 15 second-grade interviews and 12 fifth-grade interviews) were randomly selected and reviewed by two independent coders against the checklist to assess attainment of the interview objectives. For all interviews, the percentage of objectives met ranged from 50 to $100 \%$, with an overall mean of $96 \%$. Percentage of objectives met for second- and fifth-grade interviews averaged $94 \%$ and $98 \%$, respectively.

\section{RESULTS AND Discussion}

The social behaviors identified by all participant groups as important for social competence are reported in Tables 1 through 3 . All behaviors reported in the tables represent the themes that emerged from the card-sorting technique during the selective coding phase of data analysis. Thus, these behaviors suggest an adequate representation of the clusters of responses made by parent, teacher, and child participants. Social behaviors reported by second- and fifth-grade children and one or more 


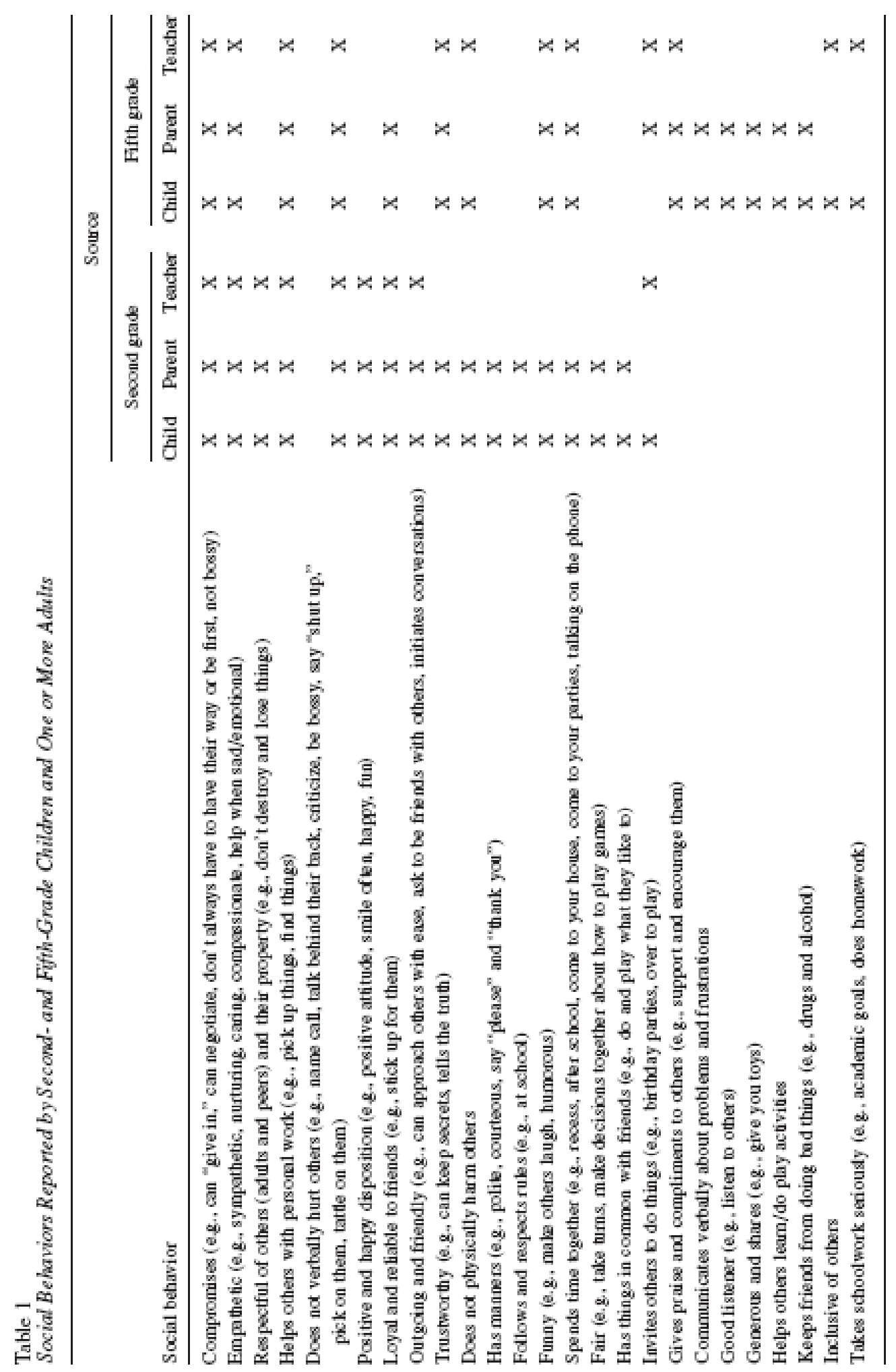




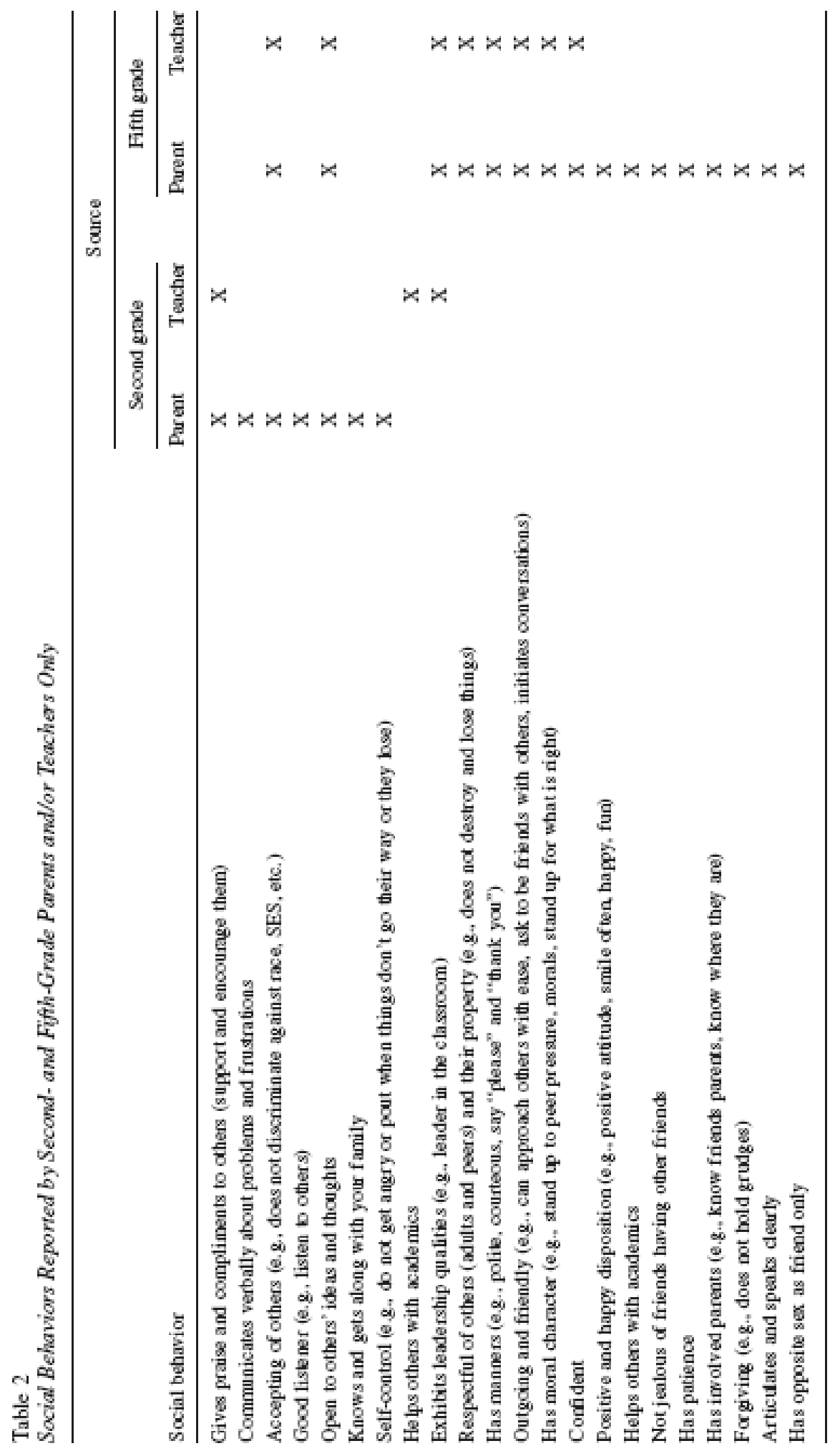


Table 3

Social Behaviors Reported by Children Only

\begin{tabular}{lrr}
\hline & Grade \\
\cline { 2 - 3 } Social behavior & 2 & 5 \\
\hline Good hygiene (e.g., clean) & $\mathrm{X}$ \\
Generous and shares (e.g., give you toys, money) & $\mathrm{X}$ & \\
Fair (e.g., take turns, make decisions together about how to play games) & $\mathrm{X}$ \\
Has things in common with friends (e.g., do and play what they like to) & $\mathrm{X}$ \\
Chooses you for their partner (e.g., recess or in gym) &
\end{tabular}

adults (i.e., parents and/or teachers) are found in Table 1. In some cases all three sources (i.e., children, parents, and teachers) reported the behavior, and in other cases only two sources reported the behavior. Social behaviors only reported by parents and teachers are found in Table 2 . Social behaviors identified only by children as important for social competence are located in Table 3.

Although some differences were found among the behaviors reported by all three sources within each grade level, substantial overlap existed among the types of behaviors reported by children, parents, and teachers (see Table 1). In second grade, children, parents, and teachers all reported that compromising, being empathetic, being respectful of others and their property, helping others with their personal work, not verbally hurting others, having a positive and happy disposition, being loyal and reliable to friends, and being outgoing and friendly were important behaviors for being a good friend. Likewise, fifth-grade children, parents, and teachers all reported that compromising, being trustworthy, being empathetic, helping others with their personal work, not verbally hurting others, giving praise and compliments to others, being funny, and spending time together were important behaviors for being a good friend. These aforementioned behaviors are important from multiple perspectives within children's environments; thus, they most likely play a significant role in the social networks of second- and fifth-grade children.

The results of this study indicate that there are specific types of behaviors that stand out as important for social competence in the second and fifth grades. It can be argued that children are the primary criterion population by which the social validity or meaningfulness of social behavior within peer networks can be measured because children, themselves, comprise these networks; hence, the behaviors reported by second- and fifth-grade children are important. Those behaviors reported by children that are likewise reported by parents and/or teachers are especially noteworthy, as these behaviors are validated by additional relevant sources within the social environment and are viewed as important from multiple perspectives.

Many of the same types of social behaviors were reported at both grade levels (i.e., compromising, empathy, help others with personal work, not verbally hurting others, loyal and reliable to friends, trustworthy, not physically harmful, funny, spend time together, invite others to do things). This suggests that some behaviors cross developmental levels in terms of their significance within the social milieus of second and fifth graders. Even though the same behaviors may be reported in the second and fifth grades, it is possible that the presentation of these social behaviors varies among the different grade levels. For example, being funny may be expressed differently in the second and 
fifth grades (e.g., making funny faces vs. telling a joke). Likewise, expressions of empathy may look very different among the second and fifth grades (e.g., asking a peer who appears sad to join in an activity vs. pats on the back and talking about problems). Further researchers may attempt to identify objectively specific manifestations of these behaviors through direct observation.

Although there are many similarities in the responses of second- and fifth-grade sources, some differences are evident. Many of the behaviors reported by second-grade children, parents, and teachers tend to be rule-governed behaviors (e.g., being respectful of others and their property, following and respecting rules, being fair, and having manners). This is not surprising considering the importance placed on rules and rule following at this age level. Second graders have attended formal schooling for less than 2 years during which time there is a strong emphasis placed on learning to adhere to the structure and boundaries of school life. It is likely that children and the adults in their lives (i.e., parents and teachers) perceive rule-governed behaviors as important for social competence given the importance placed on these behaviors at this grade-level. In comparison, many of the behaviors reported by fifth-grade sources involve verbal communication (e.g., communicating verbally about problems and frustrations, being a good listener, giving praise and compliments to others). This result is consistent with the natural developmental differences found between second- and fifth-grade children. Language-based communication is not as developed in younger children, thus behaviors involving verbal communication would be expected to have greater importance in the fifth grade as compared to the second grade.

The findings of this study highlight the richness and complexity of social competence within children's social networks. Many of the social behaviors identified by participants are not simple and discrete. For example, behaviors such as trustworthiness, empathy, having a happy disposition, being respectful of others and their property, and being loyal and reliable to friends are complex personal characteristics that cannot easily be defined. The original responses of participants that were used during the coding process to create the final behavioral categories reported in this study provide some concrete examples of the aforementioned behaviors (e.g., trustworthy is comprised of behaviors such as "keeps secrets" and "don't lie," and empathy is comprised of behaviors such as "helps you when you are sad" and "makes you feel happy when you are feeling down"). However, the complex nature of these behavioral constructs aligns closely with the innate qualities of an individual's character, rather than discrete behaviors typically assessed for or taught in social skills training.

Many of the behaviors identified in this study as important for social competence can be assessed through various social skills ratings scales; however, they are not consistently incorporated into the rating scales used to assess children. In an extensive review and factor analysis of the social skills assessed through common ratings scales Caldarella and Merrell (1997) identified five primary skill dimensions: peer relations, self-management, academic, compliance, and assertion. The identified peer relations factor was comprised of behaviors such as compliments and praises others, offers help to others, is sensitive to others' feelings (e.g., empathy and sympathy), has a sense of humor, and compromises with others. Many of these behaviors are similar to those identified in the present study (e.g., empathetic, funny, compromising). Results of Caldarella and Merrell's analysis (1997) indicate, however, that these behaviors were incorporated into only a fraction of the rating scales commonly used to assess children's social competence (i.e., occurrence rates of 52.38\%). Likewise, many of the behaviors that comprised the assertion factor (e.g., initiates conversations with others, invites peers to play, makes friends, introduces self to new people, and expresses feelings when wronged) paralleled the social behaviors identified in the present study (e.g., invites others to do things, communicate verbally about problems, spend time together). Again, however, the assertion dimension occurred in only a 
fraction of the rating scales (i.e., 33.33\%). Thus, although many of the social behaviors identified in the current study may be addressed through rating scales, assessment of these behaviors is not standard practice.

\section{Limitations}

There are several noteworthy limitations of the current study. The first concerns the restricted nature of the sample. Results are based on data from second- and fifth-grade children, parents, and teachers in two elementary schools in a mid-sized, midwestern city. Given the contextual nature of social behavior, it can be assumed that differences exist with regard to the types of social skills that are normative for children at different grade levels and in different geographic locations. Thus, conclusions cannot be made beyond the defining characteristics of the sample population. Furthermore, there are limited teacher data compared to that from children and parents. To make conclusions about the types of behaviors that are important for social competence within a particular context, efforts were made to gather information from sources within similar contexts (i.e., child, parent, and teacher data from the same grade levels at the same two schools). As such, a limited number of teachers were eligible to provide data (i.e., 4-5 second- and fifth-grade teachers per building). Grounded theory methodology generally involves collecting data until some form of data saturation is achieved. Data saturation refers to the process of collecting data until new information is no longer generated from respondents. It is likely that data saturation did not occur for the teacher data in this study because of the limited sample size; therefore, our application of grounded theory methodology is somewhat limited.

The current study is based on the fundamental theory that social behavior is contextually driven. As such, it is possible that there would be variability in responses due to the different demands and activities within school and home settings. For example, there may be different skills and abilities required to get along with others during a group project at school versus on the playground. Similarly, parents may perceive that being a good friend during extracurricular activities (e.g., Boy/Girl Scouts) may entail different behaviors than those required for being a good friend during an unstructured playtime at home. The survey questions used in the current study cover home and school settings in a broad sense and do not account for this type of setting specificity.

Another limitation concerns the slight variability of responses that comprise the behavioral categories for each data set. Due to the considerable amount of qualitative data gathered from participants, data were organized into conceptual categories to capture themes in data. Though handled in a rigorous fashion through structured coding and triangulation, some slight variation exists within the behaviors that comprise the themes that emerged from the coding process (e.g., trustworthy was comprised of responses such as "can keep secrets" and "tells the truth"). Relatedly, there is some variability in the frequency with which the responses that comprise the identified social behaviors were reported by participants. No objective data were collected on the percentage of respondents that provided specific responses. This was not possible due to the manner in which data were organized for analysis and interpretation. It was the intent of the current study to identify themes in data based on clusters of responses, rather than analysis of responses at the individual level. Although no social behavior labels were given to any one individual response, it is possible that there is some variation in the frequency with which various responses were reported by children, parents, and teachers.

Finally, the outcomes of this study are based on the subjective perceptions of parent, teacher, and child participants and are not validated through direct observations of socially competent children. Although participant sources may perceive various behaviors as important for social competence, it 
is possible that these particular behaviors are not demonstrated by socially competent children in the environment. Direct observations of competent children would provide validation for parent, teacher, and child reports.

\section{FutURe DireCtions}

Future research is needed to examine the validity and treatment utility of the assessment procedure used in this study. Criterion related validity could be assessed through direct observations of popular, socially skilled peers within social networks. Demonstration of the behaviors that characterize social competence by children perceived to be socially skilled would lend support for the validity of the assessment procedure. Furthermore, future research could examine the utility of using the behaviors identified through this assessment procedure as targets in social skills intervention. Once identified by relevant sources, specific behaviors that correspond to social competence could be taught to children with social skills difficulties. Positive changes in social functioning as measured through observations, ratings, and interviews would suggest that the contextual assessment procedure is a useful method for identifying targets for social skills treatment interventions.

The current study utilized a contextual approach to assess the behaviors that are important for social competence at two grade levels. Results indicate that, although there is some overlap among the types of behaviors reported by children, parents, and teachers in the second and fifth grades, there are some unique differences as well. Future research could examine the use of this assessment procedure with other contexts (e.g., other grade levels, types of schools, SES, geographical locations) to identify similarities and differences in behaviors that correspond to peer-related social competence. It is likely that the variation in expectations, norms, and task demands found in different contexts would produce noteworthy differences in the types of behaviors related to social competence in these environments.

The results of this study suggest that peer-related social competence cannot be easily defined by a set of discrete pro-social behaviors. There are a number of complex personal characteristics that children, parents, and teachers perceive as essential for getting along with others (e.g., trustworthiness, having a happy disposition, being loyal and reliable). Standard intervention for children with social difficulties tends to include instruction on discrete pro-social behaviors often found in social skills training packages. Unfortunately, many of the behavioral characteristics identified in this study as important for social competence are not addressed in intervention with children. One possible reason for this is that the complex behaviors identified here are not easily defined. Future research could begin to operationalize these behavioral constructs to teach them to children. Extensive observations of peer networks may be helpful to this end, as observers may be able to identify the subtle nuances involved in the expression of these behaviors (e.g., What does it look like when children "stick up" for each other, help each other when they are sad, and have a positive disposition?). Furthermore, research could examine various methods for helping children utilize the behaviors identified as important for social competence. Because many of the identified behaviors do not lend themselves to discrete steps (e.g., trustworthiness, loyalty and reliability, respectfulness,) typical methods of social skills instruction (e.g., skill instruction, modeling, role play) may not apply. Other methods of instruction could be explored to further children's knowledge and use of meaningful behaviors (e.g., use of social stories and dialogue about the relevance of important behavioral attributes). 


\section{CONCLUSiON}

Social competence is a critical factor in the development of children. Identifying behaviors that are necessary for children to get along with their peers is of the utmost importance. The types of behaviors that are expected and reinforced within children's social networks are largely determined by the individuals who function within children's environments (e.g., peers, teachers, parents). Thus, a contextual approach is needed to assess the behaviors that are meaningful and that correspond to social competence for children. The current study expanded the research literature by utilizing a contextual assessment approach to identify behaviors for social competence in the second and fifth grades. Results of this exploratory study provide an initial foundation for future research and development in this important area.

\section{REFERENCES}

Caldarella, P., \& Merrell, K.W. (1997). Common dimensions of social skills of children and adolescents: A taxonomy of positive behaviors. School Psychology Review, 26, 264-278.

Carey, S.P., \& Stoner, G. (1994). Contextual considerations in social skills instruction. School Psychology Quarterly, 9, 137-141.

Coie, J.D., \& Dodge, K. (1988). Multiple sources of data on social behavior and social status in the school: A cross age comparison. Child Development, 59, 815-829.

Cresswell, J.W. (1998). Qualitative inquiry and research design: Choosing among five traditions. Thousand Oaks, CA: Sage.

Dodge, K. (1983). Behavioral antecedents of peer social status. Child Development, 54, 1386-1399.

Elliott, S.N., \& Busse, R.T. (1991). Social skills assessment and intervention with children and adolescents: Guidelines for assessment and training procedures. School Psychology International, 12, 63-83.

Foster, S.L., Inderbitzen, H.M., \& Nangle, D.W. (1993). Assessing acceptance and social skills with peers in childhood: Current issues. Behavior Modification, 17, 255-286.

Fox, J.J., \& McEvoy, M.A. (1993). Assessing and enhancing generalization and social validity of social-skills interventions with children and adolescents. Behavior Modification, 17, 339-366.

Gresham, F.M. (1986). Conceptual issues in the assessment of social competence in children. In P.S. Strain, M.J. Guralnick, \& H.M. Walker (Eds.), Children's social behavior: Development, assessment, and modification (pp.143-179). New York: Academic Press.

Gresham, F.M. (1995). Best practices in social skills assessment. In A. Thomas \& J. Grimes (Eds.), Best practices in school psychology-III (pp. 1021-1030). Washington, DC: National Association of School Psychologists.

Gresham, F.M., \& Elliott, S.N. (1990). Social Skills Rating System: Manual. Circle Pines, MN: American Guidance Services.

Haring, T.G. (1992). The context of social competence: Relations, relationships, and generalization. In S.L. Odom, S.R. McConnell, \& M.A. McEvoy (Eds.), Social competence of young children with disabilities: Issues and strategies for intervention (pp. 307-320). Baltimore: Paul H. Brookes.

Hoier, T.S., \& Cone, J.D. (1987). Target selection of social skills for children: The template-matching procedure. Behavior Modification, 11, 137-163.

Kazdin, A.E. (1977). Assessing the clinical or applied importance of behavior change through social validation. Behavior Modification, 1, 427- 452.

Maag, J.W. (1989). Assessment in social skills training: Methodological and conceptual issues for research and practice. Remedial and Special Education, 10, 6-17.

Mash, E.J., \& Barkley, R.A. (1996). Child psychopathology. New York: Guilford Press. 
McConnell, S.R. (1987). Entrapment effects and the generalization and maintenance of social skills training for elementary school students with behavioral disorders. Behavioral Disorders, 12, 252-263.

McFall, R.M. (1982). A review and reformulation of the concept of social skills. Behavioral Assessment, 4, 133.

Merrell, K.W., \& Gimpel, G.A. (1998). Social skills of children and adolescents: Conceptualization, assessment, treatment. Mahwah, NJ: Erlbaum.

Parker, J.G., \& Asher, S.R. (1987). Peer relations and later personal adjustment: Are low-accepted children at risk? Psychological Bulletin, 102, 357-389.

Sheridan, S.M., Hungelmann, A., \& Maughan, D.P. (1999). A contextualized framework for social skills assessment, intervention and generalization. School Psychology Review, 28, 84-103.

Sheridan, S.M., \& Walker, D. (1999). Social skills in context: Considerations for assessment, intervention, and generalization. In C.R. Reynolds \& T.B. Gutkin (Eds.), The handbook of school psychology (3rd ed., pp. 686-708). New York: Wiley.

Strauss, A., \& Corbin, J. (1998). Basics of qualitative research: Grounded theory procedures and techniques. Newbury Park, CA: Sage.

Vosk, B., Forehand, R., Parker, J.B., \& Rickard, K. (1982). A multimethod comparison of popular and unpopular children. Developmental Psychology, 18, 571-575.

Walker, H.M., Irvin, L.K., Noell, J., \& Singer, G.H.S. (1992). A construct score approach to the assessment of social competence: Rationale, technological considerations, and anticipated outcomes. Behavior Modification, $16,448-474$. 